\title{
The effects of zinc supplementation on zinc, retinol and carotene levels in lactating Amazonian women
}

R. Shrimpton ${ }^{1}$ and H. Marinho ${ }^{2}$

${ }^{1}$ Dept of Global Community Health and Behavioral Sciences, Tulane School of Public Health and Tropical Medicine, New Orleans, USA.

${ }^{2}$ Laboratório de Alimentação e Nutrição, Coordenação de Ciências da Saúde, Instituto Nacional de Pesquisas da Amazónia, CP 478, Manaus, AM, Brazil.

\section{Abstract}

The effects of zinc supplementation on levels of zinc, retinol and carotene in serum and breast milk were investigated in a double blind controlled prospective study amongst 66 poor urban Amazonian mothers in 1981. The mothers predominantly breast-fed their infants for the first five months of life and took supplements from soon after birth. Milk retinol levels were already significantly higher in zinc supplemented (ZS) than non-zinc supplemented (NZS) mothers by one month post-partum, and by four months had risen significantly in the ZS mothers but fallen in NZS mothers. At four months post-partum, milk retinol levels of ZS mothers were near normal and double those of NZS mothers. The effect of zinc supplementation on these retinol levels was possibly associated with an increased absorption and utilization of dietary carotene, since milk carotene levels also increased in ZS mothers to levels three times those of NZS mothers at four months post-partum. This impact of zinc supplementation on maternal and breast milk vitamin A levels has not been shown previously and is of potential relevance where zinc and vitamin A deficiency are common.

Key words: Zinc, Vitamin A, Carotene, Breastmilk. 


\section{Introduction}

In the 1980s, zinc was found to be one of the principal dietary inadequacies in the central Amazon valley (Shrimpton 1980; Shrimpton 1984; Amoroso \& Shrimpton 1984), and a third of low-income urban workers had low serum zinc levels ( $<70 \mathrm{mg} / \mathrm{l})$, associated with similarly inadequate dietary intakes (Shrimpton et al. 1983a). The population was typically stunted, but there was not the dwarfism and sexual retardation, nor the other overt clinical signs of zinc deficiency found in the middle east (Prasad et al. 1961). There were no specific biochemical indicators of zinc deficiency (Solomons \& Shrimpton 1984) at the time of the study.

During lactation, zinc requirements of the mother increase considerably. When the study was being planned no randomized placebo-controlled zinc supplementation trials during breastfeeding existed in the literature and evidence as to whether dietary intakes influenced breastmilk zinc levels was not very conclusive. Significant differences in milk zinc levels had been observed between high income and low-income women in India (Rajalakshmi \& Srikantia 1980) while other observational studies had found no relationship between milk zinc levels and maternal dietary intakes (Vaughan et al. 1979; Vuori et al 1980) or with zinc supplement consumption (Picciano \& Guthrie 1976; Kirksey et al. 1979), albeit these studies had been done on well-nourished American women.

The amounts of vitamin A in breastmilk are relatively large, creating a high demand on any maternal stores, and one known consequence of zinc deficiency is impaired vitamin A metabolism (Smith 1980). It was thought that this could be due either to impaired mobilization of retinol from liver stores due to decreased production of retinol binding protein (RBP), and/or to impaired metabolism of vitamin $\mathrm{A}$ at the cellular level. Zinc deficiency had been shown to limit RBP production in malnourished children in India (Shingwekar et al. 1978), and to impair the efficiency of beta carotene utilization in rats (Takruri \& Thurnham 1982). Half of the dietary vitamin A amongst the poor population of Manaus came from fruit and vegetable sources (Shrimpton 1984), and especially from the carotene in the yellow cassava flour (Marinho \& Arkcoll 1981) commonly consumed in the Amazon.

At the time of this study (and to a large extent this remains true today), there was little evidence as to whether zinc supplementation in lactation would actually improve vitamin A status of the women or carotene levels in breast milk. Thus, the present study sought to determine whether supplementation during lactation would increase both zinc and vitamin A levels in lactating mothers and their breast milk. Some of the results of this study, have been partially communicated previously in scientific meetings (Shrimpton et al. 1983b; Shrimpton et.al. 1985) but have been re-analysed for this publication after including the carotene results.

\section{Methods}

The study was a double blind prospective intervention trial, with subjects sequentially assigned to experimental and placebo control groups. All pregnant women in Coroado, a peri-urban slum community adjacent to the Amazonian Research Institute (INPA) in Manaus, were located through an extensive house to house search during the month of May 1980. All women found who were in the first four months of pregnancy agreed to participate in the study and signed informed consent forms. There was no local institutional ethics committee to approve the research proposal at that time, but the 
principles of the Helsinki Treaty on human rights were observed.

During the latter part of their prenatal period, the mothers received education at monthly meetings of their local mothers' club in predominant breast feeding, oral rehydration therapy, basic hygiene, growth monitoring and immunizations. The breastfeeding recommendations were those of Jelliffe (1968) to exclusively breastfeed until six months, with no need for extra water, as the local environment, although hot, was very humid. However, since strict adherence to exclusive breastfeeding in its modern definition was not measured, we prefer using the word predominant, which carries a much lower risk of error. We do believe that most infants in the study were exclusively breast fed most of the time.

Oral rehydration salts were not yet available locally, but we got these with help from the UNICEF office in Brasilia. The mothers were also guaranteed routine pre-natal care through the local government health service. Mothers notified child birth through the mothers' club to the research team at INPA, such that contact was established by household visit within days of birth.

The experimental field observations were carried out during the period of September 1980 through to July 1981. During the study, mothers were visited three times at their homes, initially to obtain socio-economic data, and later to observe feeding practices and in a 50\% sub-sample to carry out a 24-hour recall interview of maternal food intake. Capsules for the experimental and control groups were prepared in the laboratory at INPA to contain either $15 \mathrm{mg}$ of elemental zinc in the form of its sulphate (Analar grade, Merk, Sharpe and Dome) mixed in corn starch, or a corn starch placebo containing less than $.01 \mathrm{mg}$ of elemental zinc. The prepared capsules were then labelled as either odd (control) or even (experimental) by one of the authors (RS) such that both mothers and the research team were blinded to the intervention. Systematic assignment of mothers to the experimental or control groups was done, based on notification of birth. The capsules were delivered to the mothers on a weekly basis and compliance was verified by requesting to see the envelope of capsules delivered the previous week. Mothers not consuming at least five out of seven capsules three weeks consecutively were adjudged to be not complying and excluded from the study. All mothers started on their schedule of daily capsules during the first week post-partum. All mothers were given stool tests for gastro-intestinal parasites monthly post-partum and those found positive treated using standard health service medication.

Blood, hair and milk samples were collected from mothers during household visits, performed between 9 and 11 am on days 30 and 120 post-partum, with a maximum tolerance of 3 days either way. A 5-ml blood sample was obtained by peripheral venepuncture using plastic disposable syringes with stainless steel needles (Monoject, St Luis, MO). Samples were transferred to glass centrifuge tubes and transported to the nearby laboratory in a cold box and protected from light. Within an hour, aliquots of whole blood were withdrawn for haemoglobin and haematocrit determinations.

Separated serum samples were stored frozen in plastic tubes at $-20^{\circ} \mathrm{C}$ until analysed. All glass was acid washed and plastic ware tested to confirm that they did not contribute zinc to the samples. Hair was cut from the sub occipital region and $40 \mathrm{mg}$ of the $2 \mathrm{~cm}$ nearest to the scalp collected for analysis. Approximate $5 \mathrm{ml}$ samples of foremilk were collected by manual expression by the mother into a wide mouthed plastic flask, known not to contribute zinc. The mother was asked to express milk from the fullest breast, or 
not the one the child last suckled from.

Zinc determinations were performed using flame atomic absorption spectrophotometry with a Perkin Elmer 403 fitted with deuterium arc background corrector, following manufacturers standard procedures (Perkin Elmer Corp, Norwalk, CT). Serum was prepared by wet ashing, using trichloracetic acid as described by Giroux (1975) and then aspirated. Milk zinc was diluted and aspirated direct. Hair was washed and then dry ashed and aspirated in a hydrochloric acid solution (Issac \& Johnson, 1975). Retinol and carotene in serum and milk were assayed by the spectrophotometric method of Bessey et al. (1946) as modified by Araujo \& Flores (1978). Haemoglobin was determined in venous blood by the cyanmethemoglobin method (ICNND 1963). Fat was determined in breast milk samples using the creamatocrit method (Lucas et al. 1978).

All statistical analysis was done using the SAS statistical package (SAS Institute, Cary, NC). After testing for normality of distributions, Student's T-Test and Chi-Square statistics were used where appropriate to test differences between the experimental and control groups. Individual change scores were calculated for the various serum and milk constituents analysed, using the difference between the measurement at 120 and 30 days. The presence of associations between the various serum and milk indicators was also assessed using Pearson's correlations.

\section{Results}

The flow chart of the experiment is shown in Figure 1, and of the 220 pregnant women who were initially located, the 138 women in the first four months of pregnancy were invited to participate in the study. Of these one hundred and twenty-one women notified birth and were assigned to treatment groups (61 experimental and 60 controls). Of these, 43 dropped out or were excluded before 30 days post-partum (18 experimental and 25 controls) mainly because they were not predominantly breast feeding their children as the study required. Seventy-eight mothers were participating at thirty days after birth (43 experimental and 35 controls). Of the 66 mothers who were still participating in the study at 120 days post-partum, 37 were in the experimental group and 29 were placebo controls.

The socio-economic, health and demographic characteristics of the mothers included in the study are shown in Table 1 . There were no significant differences between the experimental zinc supplemented (ZS) and non-zinc supplemented (NZS) groups of mothers for the various characteristics listed. Most of the mothers were married and literate, with an average age of 25 years, and a mean of three children already. Three quarters of the mothers were anaemic. Just less than half of the houses had toilets, with electricity and piped water only slightly more common. The gastrointestinal parasite infection rates were just over $80 \%$ at the beginning of the study, progressively diminished with treatment, and were not significantly different between the groups at any month (results not shown). Both zinc and energy intakes were slightly greater in the ZS than NZS mother at baseline and during the trial (excluding the amount provided by the supplement), but these differences were not statistically significant. 


\section{Figure 1: Flow Chart of experiment}

\section{Enrolment}

$$
\begin{aligned}
& \text { Pregnant women in Coroado assessed } \\
& \text { for eligibility }(n=220)
\end{aligned}
$$

Excluded as more than 4 months

pregnant $(n=62)$

Women in first 4 months of pregnancy $(n=138)$

Allocation

Mothers reported birth and were sequentially (randomly and blinded) allocated to supplementation group $(n=121)$

Excluded as women didn't report birth $(n=17)$

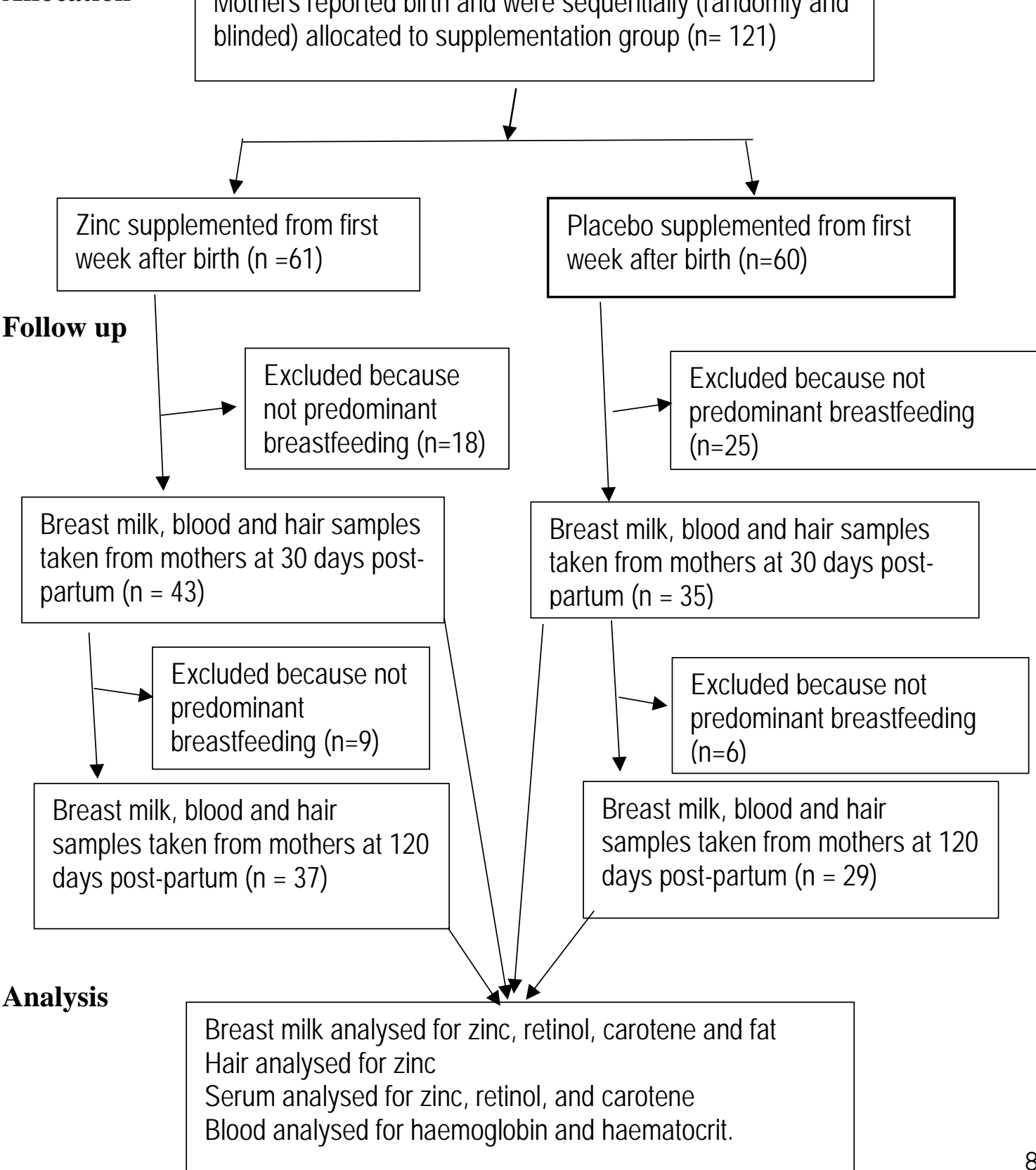


Table 1. Baseline characteristics of peri-urban lactating Amazonian mothers participating in a zinc supplementation trial ${ }^{1}$

\begin{tabular}{|l|l|l|}
\hline Characteristic & NZS (n=29) & ZS (n=37) \\
\hline Family income (Cr\$/month) & $7606(5267)$ & $6500(4237)$ \\
\hline Mothers age (years) & $25.1(6)$ & $25(5)$ \\
\hline Parity & $3.9(2.1)$ & $4.7(3.0)$ \\
\hline Single mothers (\%) & 5 & 5 \\
\hline Literate mothers (\%) & 83 & 84 \\
\hline House with toilet (\%) & 49 & 36 \\
\hline House with piped water (\%) & 66 & 43 \\
\hline House with electricity (\%) & 63 & 61 \\
\hline $\begin{array}{l}\text { Mothers with GI parasites } 30 \\
\text { days post-partum (\%) }\end{array}$ & 86 & 81 \\
\hline Mothers anaemic (\%) $^{\text {Zinc intake }{ }^{23} \text { (mg/day) }}$ & 75.8 & 75.7 \\
\hline Energy intake $^{2}$ (Mj/day) & $8.0(3.9)$ & $9.4(2.7)$ \\
\hline
\end{tabular}

${ }^{1}$ Mean (standard deviation) with significant difference* (= 95\% confidence interval) between zinc supplemented (ZS) and non-zinc supplemented (NZS) mothers across time post-partum.

${ }^{2}$ Mean of 3 twenty-four-hour recalls obtained at 30, 60, and 120 days postpartum on 19 mothers in each group

${ }^{3}$ Zinc intakes excludes the zinc content of the supplement provided.

Indicators of zinc, retinol, carotene and iron status in ZS and NZS mothers at 30 and 120 days post-partum and the changes during that period are shown in Table 2. Serum zinc levels were similar at 30 days post-partum but significantly higher at 120 days post-partum in the ZS group. The mean increase in serum zinc from 30 to 120 days post-partum was four times greater in ZS than NZS mothers and significantly so. Hair zinc levels were not significantly different in ZS and NZS mothers at 30 days or 120 days partum. From 30 to 120 days post-partum hair zinc levels rose in ZS and fell in NZS mothers, but the mean changes were not significantly different. Milk zinc levels were not significantly different between ZS and NZS mothers at 30 and 120 days post-partum. Breastmilk zinc values fell from 30 to 120 days past-partum, and although the decrease was less in the ZS than the NZS mothers, this difference was not statistically significant.

Zinc supplementation improved maternal vitamin A status, with serum retinol significantly higher in the ZS mothers compared to the NZS mothers by 120 days postpartum. The mean increase in serum retinol from 30 to 120 days was twice the size in the ZS mothers than in the NZS mothers, although not significantly different. Breastmilk retinol levels were significantly higher in the ZS than the NZS mothers both at $30(\mathrm{p}<0.05)$ and $120(\mathrm{p}<0.001)$ days post-partum. Breastmilk retinol levels fell in NZS but rose in ZS mothers during 30 and 120 days post-partum, and the mean change over the period was significantly different $(\mathrm{p}<0.05)$.

The effect of zinc supplements on carotene levels in breastmilk was the largest of all effects observed. Serum carotene levels were not significantly different between 
Table 2. Indicators of zinc, vitamin $A$ and iron status in urban Amazonian women supplemented with $15 \mathrm{mg}$ zinc/day from day 3 after delivery, by supplementation group, time and change with time post-partum ${ }^{1}$

\begin{tabular}{|c|c|c|c|c|c|c|}
\hline \multirow[t]{2}{*}{ Indicator } & \multicolumn{2}{|c|}{$\begin{array}{l}30 \text { days post- } \\
\text { partum }\end{array}$} & \multicolumn{2}{|c|}{$\begin{array}{l}120 \text { days post- } \\
\text { partum }\end{array}$} & \multicolumn{2}{|c|}{$\begin{array}{l}\text { Change from } 30 \\
\text { to } 120 \text { days }\end{array}$} \\
\hline & $\begin{array}{l}\text { NZS } \\
(n=33)\end{array}$ & $\begin{array}{l}\mathrm{ZS} \\
(\mathrm{n}=34)\end{array}$ & $\begin{array}{l}\text { NZS } \\
(n=24)\end{array}$ & $\begin{array}{l}\text { ZS } \\
(n=31)\end{array}$ & $\begin{array}{l}\text { NZS } \\
(n=24)\end{array}$ & $\begin{array}{l}\mathrm{ZS} \\
(\mathrm{n}=31)\end{array}$ \\
\hline Serum zinc (g/dl) & $\begin{array}{l}93.96 \\
(14.26)\end{array}$ & $\begin{array}{l}95.43 \\
(9.38)\end{array}$ & $\begin{array}{l}96.02 \\
(11.13)\end{array}$ & $\begin{array}{l}101.73^{*} \\
(8.76)\end{array}$ & $\begin{array}{l}1.63 \\
(10.30)\end{array}$ & $\begin{array}{l}7.23^{*} \\
(8.82)\end{array}$ \\
\hline Hair zinc (mcg/g) & $\begin{array}{l}137.09 \\
(32.16)\end{array}$ & $\begin{array}{l}126.94 \\
(29.74)\end{array}$ & $\begin{array}{l}133.97 \\
(32.42)\end{array}$ & $\begin{array}{l}145.06 \\
(45.13)\end{array}$ & $\begin{array}{l}-3.20 \\
(45.19)\end{array}$ & $\begin{array}{l}19.45 \\
(51.16)\end{array}$ \\
\hline Breastmilk zinc (g/ml) & $\begin{array}{l}2.06 \\
(1.29)\end{array}$ & $\begin{array}{l}1.87 \\
(1.17)\end{array}$ & $\begin{array}{l}1.15 \\
(0.40)\end{array}$ & $\begin{array}{l}1.41 \\
(0.79)\end{array}$ & $\begin{array}{l}-0.82 \\
(1.02)\end{array}$ & $\begin{array}{l}-0.57 \\
(1.27)\end{array}$ \\
\hline Serum retinol (g/dl) & $\begin{array}{l}38.35 \\
(16.64)\end{array}$ & $\begin{array}{l}41.53 \\
(16.81)\end{array}$ & $\begin{array}{l}40.13 \\
(13.50)\end{array}$ & $\begin{array}{l}47.24^{*} \\
(15.06)\end{array}$ & $\begin{array}{l}2.34 \\
(23.68)\end{array}$ & $\begin{array}{l}5.18 \\
(18.41)\end{array}$ \\
\hline Breastmilk retinol (g/dl) & $\begin{array}{l}35.01 \\
(17.42)\end{array}$ & $\begin{array}{l}46.41 * \\
(17.94)\end{array}$ & $\begin{array}{l}23.81 \\
(8.02)\end{array}$ & $\begin{array}{l}52.37 * \\
(15.43)\end{array}$ & $\begin{array}{l}-7.14 \\
(13.31)\end{array}$ & $\begin{array}{l}7.86^{*} \\
(17.61)\end{array}$ \\
\hline Serum Carotene (g/dl) & $\begin{array}{l}53.02 \\
(26.33)\end{array}$ & $\begin{array}{l}59.18 \\
(33.36)\end{array}$ & $\begin{array}{l}41.22 \\
(29.55)\end{array}$ & $\begin{array}{l}61.30 \\
(23.44)\end{array}$ & $\begin{array}{l}-18.31 \\
(23.49)\end{array}$ & $\begin{array}{l}1.92 \\
(44.36)\end{array}$ \\
\hline $\begin{array}{l}\text { Breastmilk Carotene } \\
\text { (g/dl) }\end{array}$ & $\begin{array}{l}27.29 \\
(24.25)\end{array}$ & $\begin{array}{l}24.32 \\
(17.38)\end{array}$ & $\begin{array}{l}13.43 \\
(4.17)\end{array}$ & $\begin{array}{l}37.47 * \\
(14.23)\end{array}$ & $\begin{array}{l}-10.12 \\
(13.93)\end{array}$ & $\begin{array}{l}19.99 * \\
(11.55)\end{array}$ \\
\hline Breastmilk fat (g/dl) & $\begin{array}{l}2.55 \\
(0.78)\end{array}$ & $\begin{array}{l}2.90 \\
(1.11)\end{array}$ & $\begin{array}{l}2.40 \\
(0.71)\end{array}$ & $\begin{array}{l}2.73 \\
(1.50)\end{array}$ & & \\
\hline Haemoglobin (g/dl) & $\begin{array}{l}10.64 \\
(1.80)\end{array}$ & $\begin{array}{l}10.69 \\
(1.41)\end{array}$ & $\begin{array}{l}11.51 \\
(1.09)\end{array}$ & $\begin{array}{l}11.32 \\
(1.52)\end{array}$ & $\begin{array}{l}0.57 \\
(1.26)\end{array}$ & $\begin{array}{l}0.37 \\
(1.67)\end{array}$ \\
\hline Haematocrit (\%) & $\begin{array}{l}39.15 \\
(4.53)\end{array}$ & $\begin{array}{l}38.73 \\
(3.74)\end{array}$ & $\begin{array}{l}40.56 \\
(2.55)\end{array}$ & $\begin{array}{l}40.91 \\
(2.89)\end{array}$ & $\begin{array}{l}0-58 \\
(3.05)\end{array}$ & $\begin{array}{l}1.85 \\
(3.37)\end{array}$ \\
\hline
\end{tabular}

${ }^{1}$ Mean (standard deviation) with significant difference* (= 95\% confidence interval) between zinc supplemented (ZS) and non-zinc supplemented (NZS) mothers across time post-partum.

the two groups at 30 days post-partum or at 120 days post-partum, despite a $35 \%$ fall in serum carotene levels in NZS mothers and a 3\% rise in ZS mothers. Milk carotene levels were essentially the same at 30 days post-partum in both groups but were three times greater in ZS than in NZS mothers at 120 days post-partum $(\mathrm{p}<0.001)$. There was a $37 \%$ fall in milk carotene levels in NZS mothers as opposed to an $82 \%$ increase in ZS mothers $(\mathrm{p}<0.05)$. 
Zinc supplementation showed no effect on milk fat levels or on maternal anaemia. Milk fat levels did not differ between ZS and NZS mothers at either stage of lactation, and there was no difference in the mean change over time. There were no differences in the mean haemoglobin and haematocrit levels in either ZS or NZS mothers at either 30 or 120 days post-partum. There were a small, equal and nonsignificant increases in both these parameters in both ZS and NZS mothers during the study.

There were no significant associations found between indicators of maternal zinc status and milk zinc levels at either time of milk collection. There was a significant positive correlation between serum zinc at 30 days post-partum and milk zinc at 120 days post-partum.

\section{Discussion}

These results suggest that at the time of the study (1981) poor peri-urban women from the central Amazon suffered from primary zinc deficiency during lactation. Zinc deficiency in the women studied is indicated by the strong positive effects of zinc supplementation during lactation on serum zinc as compared to placebo controls. The increase in serum zinc levels in the ZS lactating mothers also provides confirmation that the mothers took at least a substantial proportion of their supplements. The appropriateness of serum zinc for evaluating the impact of zinc supplementation interventions (Hess et al. 2007) as well as being a biochemical marker for population zinc status (Gibson et al. 2008) has been confirmed, though it may not be a reliable indicator of individual zinc status.

Although this is a small study, the overall generalizability of these results would still seem to be valid today. Although the dropout rate of the women during the study was quite large (about a half) this is not to be unexpected perhaps, as the mothers from this peri-urban slum community were certainly poor and pressures to return to work and to offer other sources of milk would have been large. More recent studies show that just $40 \%$ of infants are exclusively breastfeed until 6 months of age in Brazil, as well as in other towns in the Amazon (Kearns et al. 2016), and these rates are worse in the poorer segments of society.

The zinc status of lactating women in Manaus is unlikely to have improved. More recent studies in low socio-economic women from 8 towns spread across the Brazilian Amazon found similar low levels of zinc intake (Lehti 1989), as well as low levels of zinc in breast milk (Lehti 1990). The principal source of protein in the Amazonian diet back then was fish (Shrimpton 1984) and this is unlikely to have changed to any great extent. Fish is a relatively poor source of zinc as compared with meat, such as beef for example. The more commonly eaten fish are the least expensive ones, which also have the lowest zinc content (Da Rocha et al. 1982). The fish with the highest zinc concentrations such as tucunaré are the ones highest up the food chain and are the most expensive ones. Although there has been a gradual increase in items such as sugar and beef replacing traditional foods such as fish and cassava flour in the diets of the more accessible riverine communities (Nardoto et al. 2011), the consumption of beef is still small, and principally amongst the men of the family rather than the women (Silva et al. 2016). 
The lack of impact of dietary zinc supplements on milk zinc levels agrees with most other published studies. Of four zinc supplementation trials during lactation in the literature, three found no effect (Moser-Veillon \& Reynolds 1990; Krebs et al. 1995; Chierici et al 1999) and one a lower rate of decline with supplementation (Krebs et al. 1985). Just one observational study found an increased milk zinc in women taking supplements (Karra et al. 1988), while most other observational studies have failed to find a difference in maternal zinc supplement consumption or of dietary intake on milk zinc levels (Picciano \& Guthrie 1976; Kirksey et al. 1979; Feeley et al. 1983; Moser \& Reynolds 1983; Hannan et al 2009). The great majority of these studies, as well as many others (Lamounier et al. 1989: Bates and Tsuchiya 1990; Domellof et al. 2004, Nikniaz et al. 2011), all confirm that milk zinc levels fall naturally during lactation, even in wellnourished women. The slow or non-response of breastmilk zinc levels to zinc supplements possibly reflect the nature of the homeostatic mechanisms that are in play trying to maintain zinc status during lactation (Moser-Veillon 1995). Other studies carried out in lactating women from the same location in Manaus, provide examples of such mechanisms, in spite of very high levels of absorption of dietary zinc as well as reduced faecal losses (Jackson et al. 1988).

The significant correlation found in these Amazonian women between serum zinc at 30 days post-partum and milk zinc at 120 days post-partum suggests that milk zinc levels are related to zinc status, but that zinc supplementation takes time to influence milk zinc levels, if at all. There is some evidence in the literature that milk zinc levels may fall less in more prolonged lactation if mothers have a better zinc status. Hannan et al. (2009) found a significant positive association between dietary zinc intake and milk zinc levels in American women at three months post-partum, but not earlier. The only supplementation trial that found a positive effect on milk zinc, simply showed a lower rate of decline (Krebs et al. 1985). The one observational study showing increased milk zinc in women taking supplements (Karra et al. 1988) could possibly be because the American mothers had been taking supplements routinely, such as zinc-containing prenatal supplements. The positive effect of zinc supplementation on milk zinc levels in the Amazonian women studied, although not statistically significant by four months post-partum, might have become so if the change rates of the two groups had been maintained through six months. It may be that a more prolonged supplementation period, beginning in pregnancy for instance would have been more effective.

The increase in milk retinol levels from one to four months post-partum in ZS mothers, as compared to the decrease in NZS mothers is an important finding that has not been reported previously and is potentially of great global significance. Breast milk retinol levels are maintained throughout lactation in well-nourished mothers but fall with increasing length of lactation in poorly nourished mothers (WHO 1985). The milk retinol levels of the ZS Amazonian mothers four months post-partum were comparable with well-nourished women, whilst those of un-supplemented mothers fell to levels commonly found in poorly nourished mothers. Vitamin A deficiency is a public health problem in more than half of all countries, especially in Africa and South-East Asia, hitting hardest young children and pregnant women in low-income countries (WHO 2009). However, vitamin A supplementation in post-partum women is not recommended as a public health intervention (WHO 2011). This may be because low breast milk retinol levels do not consistently respond to vitamin A supplementation, with no effect in malnourished women in India (Belavady \& Gopalan 1960), yet positive responses in the Gambia (Villard \& Bates 1987) and Indonesia (Stoltzfus et.al. 
1993) as well as to vitamin A fortified foods in Central America (Arroyave et al. 1979). When effects are seen, they are often for only a short time and at an early age when vitamin A deficiency is not seen in breast fed infants. Postnatal maternal supplementation has also not been shown to influence maternal or infant mortality (Oliveira et al. 2016). It could be that the lack of impact of vitamin A supplementation during lactation in some populations may be in part due to underlying zinc deficiency.

The effect of zinc supplementation on the vitamin A concentration in breast milk was not mediated by different fat content of the milks. The concentrations of fat and retinol in breast milk vary both within a feed and during the day (Stoltzfus \& Underwood 1995), but these two conditions were standardized so that foremilk was always collected in mid-morning. The milk fat levels of this study are similar to those reported for foremilk samples in women from elsewhere in Brazil (Dorea et al. 1982). The difference in vitamin A levels in breast milk was also unlikely to be due to differences in the dietary intake of the experimental groups. Vitamin A intakes of the mothers were not studied, but unlikely to differ greatly from those reported for similar populations, which have daily intakes around $60 \%$ of the RDA with half being of vegetable origin in the form of carotenoid precursors (Shrimpton 1984; Amoroso, \& Shrimpton 1984). Assuming that the randomization method and placebo controls used resulted in no difference in vitamin $\mathrm{A}$ intakes, the question arises as to where the extra vitamin A in breast milk came from in the zinc supplemented mothers? There was a general improvement in serum retinol levels of both supplemented and placebo groups, which was probably due to the deworming of both groups, which we have shown to improve serum retinol levels in preschool children (Marinho et al. 1991).

One possible mechanism for increased retinol in breast milk of ZS mothers includes the increased mobilization of existing hepatic reserves. The retinol secreted in breast milk is principally derived from circulating RBP (Vahlquist \& Nilsson 1979). It may be that in the ZS Amazonian mothers the production of RBP was increased, allowing increased mobilization of existing hepatic reserves, as has been suggested by observations in humans with zinc deficiency associated with various pathological conditions (Solomons \& Russel 1980). Serum RBP levels were not measured in these Amazonian mothers, but if this were the principal mechanism responsible for the zinc effect, it should have been a more rapid one and not the gradual improvement in retinol levels between one and four months post-partum. It would also seem unlikely that existing hepatic reserves could maintain such a loss of vitamin A through four months of lactation in the face of an apparently inadequate intake unless some other mechanism was in play.

Another possibility is that zinc supplementation increased the absorption of retinol and carotene, both of which are very dependent on fat absorption (Borel 2003). The inter-individual variation in the absorption of carotene in humans is known to be great (Dimitrov et al. 1988). Zinc deficiency in rats has been shown to impair fat and carotene absorption (Noh \& Koo, 2003). It may be that zinc supplementation improved fat absorption in such a way that both vitamin A and carotene absorption were increased. Mechanisms that might permit such an effect could be mediated for instance through bile salt production, the composition of which has been shown to influence carotene absorption especially (El-Gorab et al. 1975).

Another possible contributing factor is the improved utilization of absorbed 
carotene. Zinc deficiency in rats has been shown to impair the efficiency of carotene utilization (Takruri \& Thurnham 1981), possibly through an effect on carotene dioxygenase activity in the intestinal mucosa. First discovered in rat tissues by Olson and Hayashi (1965), more recently the enzyme has also been identified in humans (Lakshman 2004). The activity of this enzyme, which splits carotene into retinol, has been shown to be increased in vitamin A deficient pregnant rats (Villard \& Bates 1986), suggesting that in the absence of zinc deficiency, vitamin A deficient rats are more efficient at converting carotene to retinol.

A combination of these various effects may have contributed to an increased retinol in breast milk in the zinc supplemented mothers. The improved conversion of carotene to retinol may have contributed to the improved serum retinol levels and significantly higher milk retinol levels already at one-month post-partum, despite no difference in serum or milk carotene levels at that time. Then, as maternal retinol levels improved carotene conversion rates decreased, such that increasing quantities of carotene appear in the peripheral circulation and were excreted in milk. A more recent study of zinc supplementation together with beta carotene in Indonesian mothers during pregnancy showed an improved vitamin A status of both mothers and their infants post-partum in zinc supplemented mothers but not in mothers supplemented with beta carotene alone (Dijkhuizen et al. 2004). Other studies have shown that although beta-carotene supplements during the first month postpartum did not increase carotene levels in transitional breast milk (Gossage et al. 2002), once breast feeding is established, supplements increased serum and breastmilk carotene levels without increasing retinol levels (Canfield et al. 1997).

The carotene levels measured in the Amazonian mothers were beta-carotene, as detected by the method used (Bessey et al. 1946) as modified by Araujo and Flores (1978). More modern methods have now allowed the identification of more than 700 carotenoids, of which about 50 can be found in the human diet (Zielinska et al. 2017), and carotenoids in breastmilk are largely determined by the mother's diet. Breast milk carotenoid concentrations vary greatly across countries (Canfield et al 2003) and of the five major dietary carotenoids, total provitamin A carotenoids as a group were better predictors of milk retinol than beta-carotene alone. Little is known about whether zinc nutritional status could have any influence here, but it would seem likely based on the results of this research.

Interest in the provitamin carotenoids has grown enormously since the first observations back in the eighties that increased intakes or raised serum carotene levels were associated with a decreased risk of developing cancer (Peto et al. 1981). A recent meta-analysis of prospective studies in humans confirmed that dietary or circulating beta-carotene shows an inverse association with risk of all-cause mortality (Zhao et al. 2016). A wide variation exists in the conversion efficiency of beta carotene to retinol in humans, both within studies and within individuals (Tang 2010), with food matrix and dietary fat being among the factors accredited with causing most variability. No mention is made of zinc status however.

It is possible to conclude that the predominantly breastfed infants of NZS Amazonian mothers in this study were likely to have been receiving inadequate amounts of both zinc and vitamin A by five months of age. Other studies in other parts of the world have reached similar conclusions, with predominantly breast-fed infants 
found to be zinc deficient based on plasma zinc concentrations at 4-6 months in mothers from Thailand (Dumrongwongsiri et al. 2015), and from Serbia (Djurovic et al. 2017). These results are likely to be relevant to the estimated $17 \%$ of the world's population with an inadequate zinc intake, especially those in Asia and Africa where the prevalence is highest (Wessells and Brown 2012).

It would seem important to try and improve zinc status during lactation in populations at risk of zinc deficiency. Improving zinc status through dietary diversification is not an easy task however as zinc content is related to protein content and availability is generally better in animal protein sources, all of which has price implications (Gibson and Anderson 2009). Supplementation and fortification are additional options for improving zinc status. Tackling zinc deficiency in isolation is considered inappropriate however (Shrimpton et al 2005) and including zinc in multiple micronutrient supplementation and fortification interventions and promoting their use through existing programmes aimed at tackling anaemia for example will be less disruptive, avoiding further fragmentation of health service interventions. Indeed, zinc together with iron supplements have been shown recently to have a greater effect on carotene absorption than zinc supplements alone (Kana-Sop et al. 2015).

Acknowledgements: This study was funded by the Brazilian Scientific and Technological Research Council (CNPq). Marie Ruel provided valuable insights and assistance with the statistical analysis.

\section{References}

Amoroso M.C.M, Shrimpton, R. (1984). The effect of income and length of urban residence on food patterns, food intake, and nutrient adequacy in an Amazonian periurban slum population. Ecology of Food and Nutrition. 14:307-323.

Araujo, C.R.C., Flores, H. (1978). Improved spectrophotometric vitamin A assay. Clinical Chemistry. 24:386.

Arroyave, G., Aguilar, J.R., Flores, M., Guzman, M.A. (1979). Evaluation of sugar fortification with vitamin A at the national level. PAHO publication No 384, Washington DC.

Bates C.J., Tsuchiya H. (1990). Zinc in breast milk during prolonged lactation: comparison between the UK and the Gambia. Eur J Clin Nutr. 44(1): 61-69

Belavady, B., Gopalan, C. (1960). Effect of dietary supplementation on the composition of breast milk. Indian Journal of Medical Research. 48: 518-523.

Bessey, O.A., Lowry, O.H., Brock, M.J., and Lopez, J.A. (1946). The determination of vitamin A and carotene in small quantities of blood serum. J. Biol. Chem. 166: 177-188.

Borel P (2003). Factors affecting intestinal absorption of highly lipophilic food micro constituents (fat-soluble vitamins, carotenoids and phytosterols). Clin. Chem. Lab. Med. 41:979-994 
Canfield, L.M., Giuliano, A.R., Neilson, E.M., Yap, H.H., Graver, E.J., Cui, H.A., Blashill, B.M. (1997). Beta Carotene in breast milk and serum is increased after a single beta carotene dose.Am J Clin Nutr. 66: 52-61.

Canfield, L.M., Clandin, M.T., Davies, D.P., Fernandez, M.C., Jackson, J., Hawkes, J., Goldman, W.J., Pramuk, K., Reyes, H., Sablan, B., Sonobe T, Bo X. (2003).

Multinational study of major breastmilk carotenoids of healthy mothers. Eur J Nutr 42: 133-141.

Chierici R, Saccomandi D, Vigi V (1999). Dietary supplements for the lactating mother: influence on the trace element content of milk. Acta Paediatr Suppl. 88(430):7-13.

Da Rocha YR, Aguiar JPL, Marinho HÁ, Shrimpton R (1982). Aspectos nutritivos de alguns peixes da Amazónia. Acta Amazonica. 12(4): 787-794.

Dijkhuizen MA, Wieringa FT, West CE, Muhilal (2004). Zinc plus beta-carotene supplementation of pregnant women is superior to beta-carotene supplementation alone in improving vitamin A status in both mothers and infants. Am J Clin Nutr. 80(5):1299307

Dimitrov, N.V., Meyer, C., Ullrey, D.E., Chenoweth, W., Michelakis, A. Malone, W., Boone, C., Fink, G. (1988) Bioavailability of beta-carotene in humans. American Journal of Clinical Nutrition. 48: 298-304.

Djurović D, Milisavljević B, Mugoša B, Lugonja N, Miletić S, Spasić S, Vrvić M (2017). Zinc concentrations in human milk and infant serum during the first six months of lactation. J Trace Elem Med Biol. 41:75-78.

Domellof M, Lonnerdal B, Dewey KG, Cohen RJ, Hernell O (2004). Iron, zinc, and copper concentrations in breast milk are independent of maternal mineral status. Am J Clin Nutr. 79: 111-5.

Dorea, J.G., Horner, M.R., Bezerra, V.L.A. (1982). Correlation between changeable human milk constituents and milk intake in breast-fed babies. Journal of Pediatrics. 101: 80-83.

Dumrongwongsiri O, Suthutvoravut U, Chatvutinun S, Phoonlabdacha P, Sangcakul A, Siripinyanond A, Thiengmanee U, Chongviriyaphan N (2015). Maternal zinc status is associated with breast milk zinc concentration and zinc status in breastfed infants aged 4-6 months. Asia Pac J Clin Nutr. 24(2):273-80.

El-Gorab, M.I., Underwood, B.A., Loerch, J.D. (1975). The role of bile salts in the uptake of beta-carotene and retinol by everted gut sacs. Biochimica et Biophysica Acta. 401: 265-277.

Feeley, R.M., Eitenmiller, R.R, Benton Jones, J., Barnhart, H. (1983). Copper, iron, and zinc content of human milk at early stages of lactation. American Journal of Clinical Nutrition. 37: 443-448

Gibson RS, Hess SY, Hotz C, Brown KH (2008). Indicators of zinc status at the 
population level: a review of evidence. B J Nutr. 99 Suppl 3: S14-S33.

Gibson, R and Anderson, V (2009). A review of interventions based on dietary diversification or modification strategies with the potential to enhance intakes of total and absorbable zinc. Food Nutr. Bull. 30: S108-143.

Giroux, E.L. (1975). Determination of zinc distribution between albumin and alpha2 macroglobulin in human serum. Biochemical Medicine 12: 258-266.

Gossage CP, Deyhim M, Yamini S, Douglass LW, Moser-Veillon PB (2002).

Carotenoid composition of human milk during the first month postpartum and the response to beta-carotene supplementation. Am J Clin Nutr. 76(1):193-7

Hannan MA, Faraji B, Tanguma J, Longoria N, Rodriguez RC (2009). Maternal milk concentration of zinc, iron, selenium, and iodine and its relationship to dietary intakes. Biol Trace Elem Res.127(1):6-15.

Hess SY, Peerson JM, King JC and Brown KH (2007). Use of serum zinc concentration as an indicator of population zinc status. Food and Nutrition Bulletin 28(3): S403-S429.

Hytten FE (1955). Clinical and chemical studies in human lactation. IV Trends in milk composition during the course of lactation. BMJ. (1): 249-255

ICNND (Interdepartmental Committee on Nutrition for National Defense) (1963). Manual for nutrition surveys. 2nd Ed. National Institute of Health, Bethesda. 327p.

Issac, R.A., Johnson, W.C. (1975). Collaborative study of wet and dry ashing techniques for the elemental analysis of plant tissue by AAS. Journal of the Association Of Analytical Chemists. 58: 436-440.

Jackson M.J., Giugliano R., Giugliano, L.G., Oliveira, E.F., Shrimpton, R (1988). Stable isotope studies of zinc nutrition in slum-dwelling lactating women in the Amazon valley. British Journal of Nutrition. 59: 193-203.

Jelliffe DB. (1968). Infant nutrition in the subtropics and tropics. Geneva: World Health Organization.

Kana-Sop MM, Gouado I, Achu MB, Van Camp J, Amvam Zollo PH, Schweigert FJ, Oberleas D, Ekoe T (2015). The Influence of Iron and Zinc Supplementation on the Bioavailability of Provitamin A Carotenoids from Papaya Following Consumption of a Vitamin A-Deficient Diet. J Nutr Sci Vitaminol (Tokyo). 61(3):205-14.

Karra, M.V., Kirksey, A., Galal, O., Bassily, N.S., Harrison, G.G., Jerome, N.W. (1988). Zinc, calcium and magnesium concentrations in milk from American and Egyptian women throughout the first 6 months of lactation. American Journal of Clinical Nutrition. 47: 642-648.

Kearns AD, Castro MC, Lourenço BH, Augusto RA, Cardoso MA; ACTION Study Team (2016). Factors Associated with Age at Breastfeeding Cessation in Amazonian Infants: Applying a Proximal-Distal Framework. Matern Child Health J. 20(7):1539- 
48.

Kirksey, A., Ernst, J.A., Roepke, J.L., Tsai, T.L. (1979). Influence of mineral intake and use of oral contraceptives before pregnancy on the mineral content of human colostrum and of more mature milk. American Journal of Clinical Nutrition. 32: 30-39.

Krebs, N.F., Hambidge, K.M., Jacobs, M.A., Rasbach, J.O. (1985). The effects of dietary zinc supplement during lactation on longitudinal changes in maternal zinc status and milk zinc concentrations. American Journal of Clinical Nutrition. 41: 560-570.

Krebs NF, Reidinger CJ, Hartley S, Robertson AD, Hambidge KM (1995). Zinc supplementation during lactation: effects on maternal status and milk zinc concentrations. Am. J Clin Nur. 61(5): 1030-6

Lakshman MR (2004). Alpha and Omega of Carotenoid Cleavage. J. Nutr. 134: 241S245S.

Lamounier JA, Danelluzzi JC, Vannucchi H (1989). Zinc concentrations in human milk during lactation: a 6-month longitudinal study in southern Brazil. J Trop Pediatrics 35: 31-34.

Lehti KK (1989). Iron, folic acid and zinc intakes and status of low socio-economic pregnant and lactating Amazonian women. Eur J Clin Nutr. 43(8):505-13.

Lehti KK (1990). Breast milk folic acid and zinc concentrations of lactating, low socioeconomic, Amazonian women and the effect of age and parity on the same two nutrients. Eur J Clin Nutr. 44(9):675-80.

Lucas, A., Gibbs, J.A.H., Lyster, R.L.J., Baum, J.D. (1978). Creamatocrit: simple clinical technique for estimating fat concentration and energy value of human milk. British Medical Journal. 1, 1081-1020.

Marinho HA and Arkcoll DB (1981). Estudo sobre caroteno em algumas variedades amazônicas de mandioca (Manhihot esculenta Crantz). Acta Amazonica. 11: 71-76.

Marinho HA, Shrimpton R, Giugliano R, Burini RC (1991). Influence of enteral parasites on the blood vitamin A levels in preschool children orally supplemented with retinol and/or zinc. Eur J Clin Nutr. 45(11):539-44.

Moser PB, Reynolds RD (1983). Dietary zinc intake and zinc concentrations of plasma, erythrocytes and breast milk in antepartum and postpartum lactating and nonlactating women: a longitudinal study. American Journal of Clinical Nutrition. 38: 101-108.

Moser-Veillon, PB (1995). Zinc needs and homeostasis during lactation. Analyst. 120: 895-897.

Moser-Veillon PB, Reynolds RD (1990). A longitudinal study of pyridoxine and zinc supplementation of lactating women. Am J Clin Nutr. 52(1):135-41.

Nardoto, G. B., Murrieta, R. S. S., Prates, L. E. G., Adams, C., Garavello, M. E. P. E., 
Schor, T., et al. (2011). Frozen chicken for wild fish: Nutritional transition in the Brazilian Amazon region determined by carbon and nitrogen stable isotope ratios in fingernails. American Journal of Human Biology, 23, 642- 650.

Nikniaz L, Mahdavi R, Gargari BP, Gayem-magami SJ, Niknia Z (2011). Maternal body mass index, dietary intake and socioeconomic status: differential effects on breast milk zinc, copper and iron content. Health Promotion Perspectives, 1(2): 140-146.

Noh SK, Koo SI (2003). Low zinc intake decreases the lymphatic output of retinol in rats infused intraduodenally with Beta Carotene. J Nutr Biochem. 14: 147-153

Oliveira, J. M., Allert, R., East, C. E. (2016). Vitamin A supplementation for postpartum women. Cochrane Database of Systematic Reviews. DOI: 10.1002/14651858.CD005944.pub3

Olson J. A., Hayaishi O. (1965). The enzymatic cleavage of beta-carotene into vitamin A by soluble enzymes of rat liver and intestine. Proc. Natl. Acad. Sci. U.S.A. 54: 13641369.

Peto R., Doll R. Buckley J.D., Sporn, M.B. (1981). Can dietary beta-carotene materially reduce human cancer rates? Nature. 290: 201-208.

Picciano, M.F., Guthrie, H.A. (1976). Copper, iron, and zinc contents of mature human milk. American Journal of Clinical Nutrition. 29: 242-254.

Prasad, A.S., Halsted, J.A., Nadimi, M. (1961). Syndrome of iron deficiency anemia, hepatosplenomegaly, hypogonadism, dwarfism and geophagia. American Journal of Medicine. 31: 532-546.

Rajalakshmi K., Srikantia S.G. (1980). Copper, zinc, and magnesium content of breast milk of Indian women. American Journal of Clinical Nutrition. 33: 664-669.

Shingwekar AG, Mohanram M, Reddy V (1979). Effect of zinc supplementation on plasma levels of vitamin A and retinol binding protein in malnourished children. Clinica Chimica Acta. 93: 97-100.

Shrimpton R (1980). Studies on Zinc Nutrition in the Amazon Valley. PhD Thesis. London School of Hygiene and Tropical Medicine, University of London.

Shrimpton, R (1984). Food consumption and dietary adequacy according to income in 1200 families, Manaus, Amazonas, Brazil, 1973-1974. Archivos Latinoamericanos de Nutricion. 34: 617-629.

Shrimpton, R., Franca, T.S., Rocha, Y.S., Golden, M.H.N. (1983a). Estudos sobre o estado nutricional em relacao ao zinco na Amazonia 1. Niveis de zinco no sorro e ingestao de zinco em operarios de Manaus, 1978. Acta Amazonica. 13: 73-94

Shrimpton, R., Marinho, H.A., Rocha, Y.S., Alencar, F.H. (1983b). Zinc supplementation in urban Amazonian mothers: concentrations of zinc and retinol in maternal serum and milk. Proc. Nut. Soc. 42(3): 122A 
Shrimpton R, Alencar FH, Vasconcelos JC, Roche YR (1985). Effect of maternal zinc supplementation on the growth and diarrhoeal status of breastfed infants. Nutrition Research Suppl 1: 338-342.

Shrimpton R, Gross R, Darnton-Hill I, Young M (2005). Zinc deficiency: what are the most appropriate interventions? BMJ. 330: 347-9

Silva RJ, Garavello MEPE, Nardoto GB, Mazzi EA, Martinelli LA (2016). Factors influencing the food transition in riverine communities in the Brazilian Amazon. Environ. Dev. Sustain.18:1-16.

Smith. J.C. (1980). The vitamin A-zinc connection: a review. Ann NY Acad Sci. 355:62-75

Solomons N.W., Russel R.M. (1980). The interaction of vitamin A and zinc: implications for human nutrition. American Journal of Clinical Nutrition. 33: 20312040 .

Solomons N.W., Shrimpton R. (1984). Zinc in: Tropical and Geographic Medicine, Warren K.S., Mahmoud A.A.F. (Eds). McGraw Hill, New York, pp 1059-1063.

Stoltzfus RJ, Hakimi M, Miller KW, Rasmussen KM, Dawiesah S, Habicht JP, Dibley MJ (1993). High dose vitamin A supplementation of breast-feeding Indonesian mothers: effects on the vitamin A status of mother and infant. J Nutr. 123(4):666-75.

Stoltzfus RJ, Underwood BA (1995). Breast-milk vitamin A as an indicator of the vitamin A status of women and infants. Bull WHO 73(5): 703-711

Takruri H.R.H., Thurnham D. (1982). Effect of zinc deficiency on the conversion of B carotene to retinol as indicated by liver stores. Proceedings of the Nutrition Society. 41: 53A

Tang G (2010). Bioconversion of dietary provitamin A carotenoids to vitamin A in humans. Am J Clin Nutr. 91(suppl): 1468S-73S

Vahlquist A, Nilsson S (1979). Mechanisms for vitamin A transfer from blood to milk in rhesus monkeys. J Nutr 109:1456-1463

Vaughan, L.A., Weber, C.W., Kemberling, S.R. (1979). Longitudinal changes in the mineral content of human milk. American Journal of Clinical Nutrition. 32: 2301-2306.

Villard L., Bates C.J. (1986). Carotene dioxygenase activity in rat intestine: effects of vitamin A deficiency and pregnancy. British Journal of Nutrition. 56: 115-122.

Villard L., Bates C.J. (1987). Effect of vitamin A supplementation on plasma and breast milk vitamin A levels in poorly nourished Gambian Women. Human Nutrition: Clinical Nutrition. 41C: 47-58

Vuori E., Makinen S.M., Kara R., Kuitunen P. (1980). The effects of dietary intakes of 
copper iron, manganese, and zinc on the trace element content of human milk. American Journal of Clinical Nutrition. 33: 227-231.

Wessells KR, Brown KH (2012). Estimating the global prevalence of zinc deficiency: results based on zinc availability in national food supplies and the prevalence of stunting. PloS One. 7: e50568.

WHO (1985). The quantity and quality of breast milk. Report on the WHO collaborative study on breast-feeding. Geneva: World Health Organization.

WHO (2009). Global prevalence of vitamin A deficiency in populations at risk 19952005. WHO Global Database on Vitamin A Deficiency. Geneva: World Health Organization.

WHO (2011). Guideline: Vitamin A supplementation in postpartum women. Geneva: World Health Organization.

Zhao LG, Zhang QL, Zheng JL, Li HL, Zhang W, Tang WG, Xiang YB (2016).

Dietary, circulating beta-carotene and risk of all-cause mortality: a meta-analysis from prospective studies. Sci Rep. 6:26983.

Zielinska MA, Wesolowska A, Pawlus B, Hamulka J (2017). Health effects of carotenoids during pregnancy and lactation. Nutrients 9: 838: 1-25. 